\title{
GOOD ENGINEERING MATERIALS SHOULD NOT BE MISUSED
}

\author{
FrankLIN L. EvERETT \\ Associate Professor of Engineering Mechanics \\ University of Michigan, Ann Arbor, Mich.
}

New names of important materials are appearing in our everyday reading and in the technical literature. These include both ferrous and non-ferrous metals, plastics and even substances found abundantly on the surface of the earth. It has been said that almost anything can be made but that it is the particular problem of the engineer to see that it is made economically. The engineer is constantly making decisions involving the selection of the most suitable material and the proper shape and the best design. Moreover, he must arrive at a workable solution in a reasonable time so that people may use his product. There is always an opportunity to pursue the problem of making later improvements.

This article literally hits some high spots by naming some extremely interesting new materials which have exhibited outstanding properties such as high strength, low density, excellent resistance to chemical deterioration and destruction by high temperature.

DUKTILIRON is the trade name of the International Nickel Company for the process it will license to common grey iron foundries for making a new high-strength and high-elongation iron out of their regular grey cast iron. This will be accomplished by adding a magnesium alloy (almost any alloy) containing about 15 per cent $\mathrm{Mg}$, to the grey iron at $2750^{\circ} \mathrm{F}$, in the ladle before the iron is poured. Some of the magnesium comes out to the surface of the molten iron as slag but about 0.6 per cent $\mathrm{Mg}$ is residual in an uncombined state. The amazing result is the production of spheroidal graphite with consequent marked improvement of mechanical properties.

The International Nickel Company has made great research advances over the original patented process of Nodular iron by the British. In the British process Cesium instead of Magnesium was used.

In the research program on Duktiliron, it has been found that the tensile strength increases as the content of silicon is increased from 0 to 5.5 per cent; and the ductility decreases as the amount of carbon increases from 2 to 4.5 per cent. The maximum tensile strength of $110,000 \mathrm{lbs}$./sq. in. and 30 per cent elongation has been obtained by subjecting the material to a heat treatment.

Duktiliron is intended to compete with the usual malleable iron. It is cheaper even now. Malleable iron has a tensile strength of about 
$100,000 \mathrm{lbs} . / \mathrm{sq}$. in. and an elongation of 18 per cent. Malleable iron must be cast white iron, which requires chilling and therefore sections up to a maximum of only about 2 inches can be made. Also the malleabilizing treatment requires about seven days. Duktiliron is in all respects superior to common grey iron castings, except cost. It now is perhaps 30 per cent more expensive than grey iron. A good grey iron containing $1.5 \mathrm{Ni}$ and $0.5 \mathrm{Mo}$ has a tensile strength of 65,000 Ibs./sq. in. and less than 0.5 per cent elongation.

The disadvantages of DUKTILIRON are the necessity for the high soaking temperature of $2750^{\circ} \mathrm{F}$. in the cupola or electric furnace and the necessity for using a basic furnace lining. Some success has been obtained recently wherein the usual acid furnace lining was employed.

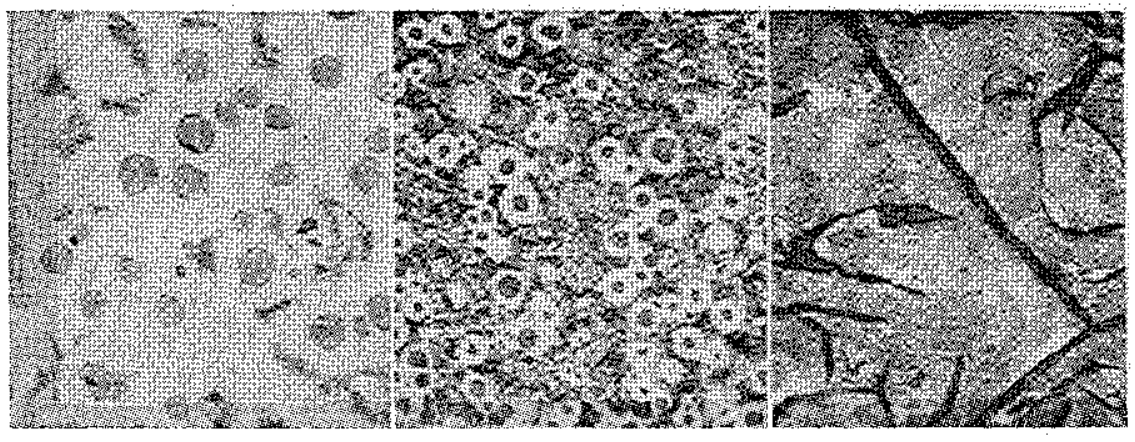

a

$\mathrm{b}$

c

a. DUKTILIRON (As Cast). Showing spheroidal graphite.

b. DUKTILIRON (Annealed). Showing numerous spheroidal graphite particles.

c. COMMON GRA Y CAST IRON. Showing flake graphite (like Corn Flakes).

Annealing at $1650^{\circ} \mathrm{F}$. and cooling the parts in the furnace has improved the mechanical properties of DUKTILIRON. This process is accomplished within a 24 -hour period.

An extensive research investigation for the International Nickel Company is being conducted at the University of Michigan.

SEMINOLE is the high-strength steel produced by the Allegheny Ludlum Steel Corporation. A typical chemical analysis shows 0.49 $\mathrm{C}, 0.25 \mathrm{Mn}, 0.69 \mathrm{Si}, 2.17 \mathrm{Wo}, 1.54 \mathrm{Cr}$ and $0.25 \mathrm{Va}$. This material is an especially high shock-resisting tool steel. When it is properly heat treated by quenching in oil from $1750^{\circ} \mathrm{F}$. and drawn at $600^{\circ} \mathrm{F}$., it attains the tremendous strength of about $297,500 \mathrm{lbs}$. per sq. in. It remains elastic almost until breakage occurs, making it an excellent spring material.

ALUMINUM and its alloys can hardly be called new materials. They have such a high strength and low weight that appropriate recognition should be given. Duralumin designated as 17 ST by the 
Aluminum Company of America is easily the most widely known aluminum alloy. Containing $95 \mathrm{Al}, 4 \mathrm{Cu}, 0.5 \mathrm{Mn}$, and $0.5 \mathrm{Mg}$ it reaches a value of $58,000 \mathrm{lbs}$. per sq. in. ultimate strength in tension. It has a density of about one third that of steel. It deforms elastically about three times that of steel. Great technical advances have been made within the last year in welding and soldering aluminum alloys.

$M A G N E S I U M$ has been alloyed by the Dow Chemical Company into many commericially important products. Dowmetal FS-1 is fabricated into sheets, rods and tubing containing $96 \mathrm{Mg}, 3 \mathrm{Cu}$, and 1.0 $\mathrm{Zn}$, has an ultimate strength ranging between 35,000 to $42,000 \mathrm{lbs}$. per sq. in. It is less than one-quarter the density of steel and the flexibility of magnesium alloys is a little over four times as great as steel.

GEON plastic is produced by the B. F. Goodrich Co. It is polyvinyl chloride which is variously added to plasticizers. The Houghton Laboratories, for example, which is one of the several concerns which compound the Geon plastic, markets two products. Hysol 3000 is a. soft rubber-like material when properly heated in molds to about $350^{\circ} \mathrm{F}$. for about an hour. It has a strength of about $2400 \mathrm{lbs}$. per sq. in. and a density of $0.0425 \mathrm{lb}$. per cu. in. A much firmer substance is Hysol 6000 which has a strength of about 11,370 lbs. per sq. in. Both of these materials are reasonably resistant to chemical action.

SILASTIC is a Dow Corning silicone rubber product possessing great ductility, resistance to chemical deterioration and capable of withstanding extreme temperatures. It can be used from $-70^{\circ} \mathrm{F}$.to $500^{\circ} \mathrm{F}$. It resists weather, hot oils and chemicals. It can be molded and extruded and has a Durometer range from 45 to 85 . Its tensile strength is in the range from 360 to $700 \mathrm{lbs}$. per sq. in. and it has an elongation from 85 to 250 per cent. It is $1 \frac{1}{2}$ times as strong as organic rubber. Silastic is not competitive with organic rubber in the temperature range from $-40^{\circ} \mathrm{F}$. to $200^{\circ} \mathrm{F}$. The density values range from 0.043 to $0.083 \mathrm{lb}$. per cu. in.

ORLON, produced by E. I. DuPont De Nemours \& Co., is a most remarkable plastic acrylic fiber. It is obtained in the from of a skein of continuous filament yarn of high strength, ranging from 71,000 to 79,000 lbs. per sq. in. It has an elongation of 15 to 17 per cent. Orlon resists heat up to $300^{\circ} \mathrm{F}$., certain chemicals, and sunlight, making it excellent for textiles. It is replacing Nylon for use in parachutes and airplane towing cords. Under exposure to outdoor elements, Orlon will outlast many times such materials as silk, rayon, and cotton. The combination of high strength and a low density of $0.042 \mathrm{lb}$. 
per cu. in. makes Orlon one of the finest commercial materials based on a strength-to-weight ratio.

KAYLO is the new insulating material manufactured from sand by the Owens-Illinois Glass Co. It is made in the form of structural fireproof insulating block with or without steel reinforcing. Although Kaylo is intended to exhibit reasonable resistance to flexure, this material is essentially intended for compressive loadings. The density is about $0.115 \mathrm{lb}$. per cu. in. Other forms of Kaylo are in heat insulating block, firedoors, pipe insulation, roof tile and laminated panels.

One of the many ways by which the engineer evaluates materials is by the so-called strength-weight ratio. Although it is most common to base these ratios on the working or safe stress which may be some arbitrary fraction of the ultimate tensile strength, for the purpose of this discussion the accompanying table shows the ratio of the ultimate tensile strength and the density. Besides considering other factors such as cost, rigidity, space requirements, availability and the like, the engineer frequently selects the material which gives the highest strength-to-weight ratio. This consideration is particularly important in the design of airplanes, ships and other transportation devices.

\begin{tabular}{lclrr}
\hline \hline \multicolumn{1}{c}{ Material } & $\begin{array}{c}\text { Tensile Strength } \\
\text { (lbs. per sq. in.) }\end{array}$ & $\begin{array}{c}\text { Density } \\
\text { (lbs. per } \\
\text { cu. in.) }\end{array}$ & $\begin{array}{c}\text { Strength- } \\
\text { Weight } \\
\text { Ratio }\end{array}$ & Rank \\
\hline Ductiliron & 110,000 & 0.260 & 420,000 & 5 \\
Malleable iron & 100,000 & 0.260 & 382,000 & 6 \\
Alloy Grey Cast Iron & 65,000 & 0.260 & 249,000 & 8 \\
Common Grey Cast Iron & 20,000 & 0.260 & 76,500 & 10 \\
Seminole steel & 297,500 & 0.283 & $1,044,000$ & 2 \\
Structural carbon steel & 60,000 & 0.283 & 213,000 & 9 \\
Duralumin, 17ST & 58,000 & 0.098 & 590,000 & 4 \\
Dowmetal, FS-1 & 38,500 (av.) & 0.064 & 600,000 & 3 \\
Geon plastic & 2,400 & 0.0425 & 56,000 & 11 \\
$\quad$ Hysol 3000 & 11,370 & 0.0413 & 275,000 & 7 \\
$\quad$ Hysol 6000 & 360 & 0.043 & 8,400 & 15 \\
Silastic & 700 & 0.083 & 8,500 & 14 \\
$\quad$ 45 Durometer & 75,000 (av.) & 0.042 & $1,780,000$ & 1 \\
$\quad 85$ & 175 & 0.0115 & 15,200 & 13 \\
Orlon yarn & 500 (comp.) & 0.0115 & 43,700 & 12 \\
Kaylo & & & & \\
& & & & \\
\hline
\end{tabular}

Certainly some brief remarks should be made about shapes. It is well known, for example, that a tubular member is generally well adapted to situations involving compressive loadings. I-beams for bending loads and simple prismatical bars for cases of tension loadings. 


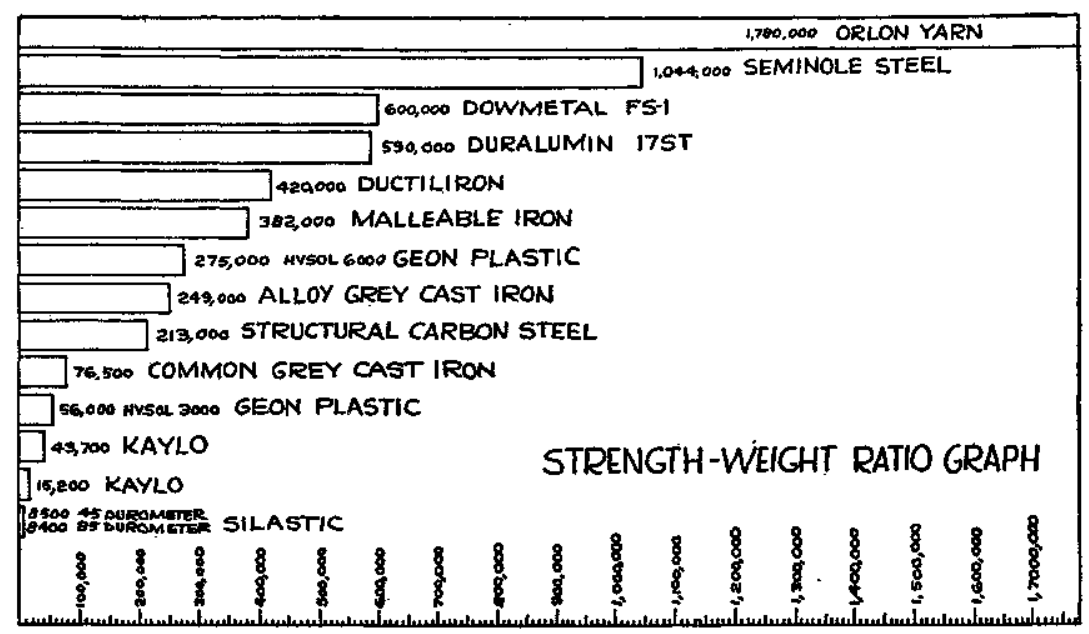

When a failure occurs in a machine or structure, it is usual to replace the part by one having just a little more material. By means of several illustrations, it will be readily understood that not only more material may make the structure weaker but actually it is sometimes better to remove material to improve the strength.

A prismatical beam may be subjected to bending as shown in the accompanying figure.

BEAMS SUBJECTED TO BENDING-REMOVE MATERIAL TO

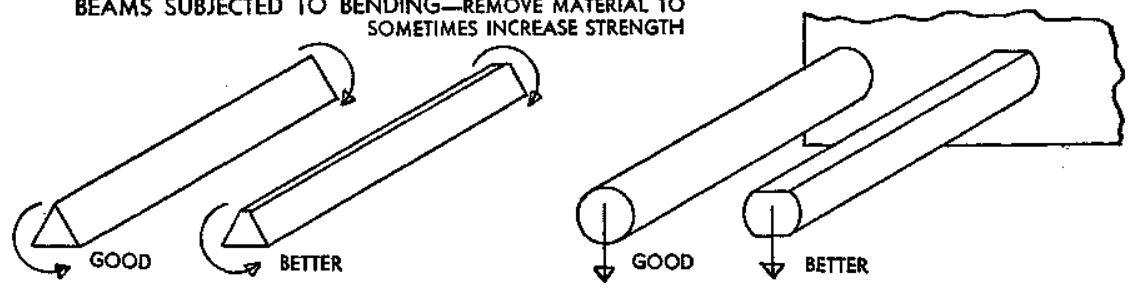

When the beam is bent the upper surface is stretched in tension. If there is only a small amount of material in this location as in the cases of the circular and triangular cross sections, it is better to remove the material which would otherwise be most highly stressed.

Most commonly actual machines and structures require more complicated designs involving connections of members of different sizes.

By two slightly more complicated illustrations, the removal of the material is recommended in the vicinity of the junctions of small and large cross sections so as to allow for greater flexibility and lower stresses. The figure (see next page) shows a freight car axle.

The propellers of lake freighters were found to break off after metal had been added in new designs as shown in the figures. 


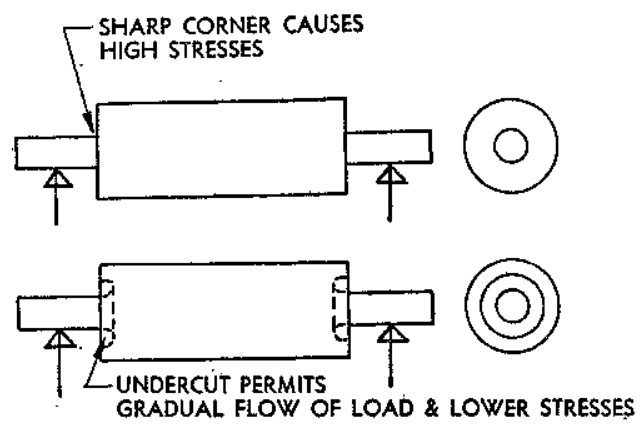

FREIGHT CAR AXLE

An effort was made to cover the heads of the bolts holding the propellers onto the hub so as to "streamline" the design. The flexibility of the construction however, was lost and vibration and fatigue resulted in the breaking of the propellers.
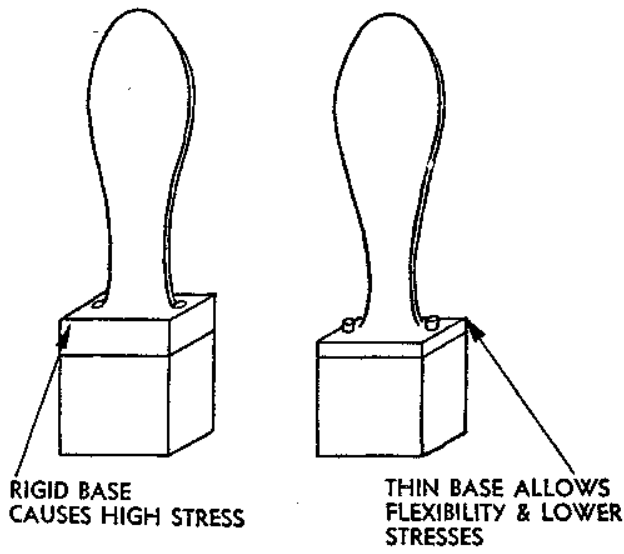

\section{SHIP PROPELLER}

The "Safe edge" drinking glass made by the Owens-Illinois Glass Co. is strengthened by blowing air onto the upper edge of the hot glass. This produces a favorable combination of surface compression and interior tension. The resulting tumbler will withstand about seven times the shock compared with an ordinary tumbler.

One of the greatest examples of the misuse of good engineering materials is in the case of concrete in sidewalks, curbs and pavements. Concrete, like most materials, expands and contracts due to the rise and fall of temperature. Concrete, unlike most materials, grows under the continued exposure to wet and dry weather conditions. The provision for expansion is frequently made to account for temperature fluctuations but any casual observer will detect countless 
broken sidewalks, curbs and pavements due to the crushing loads produced by the growth of concrete subjected to moisture. Probably

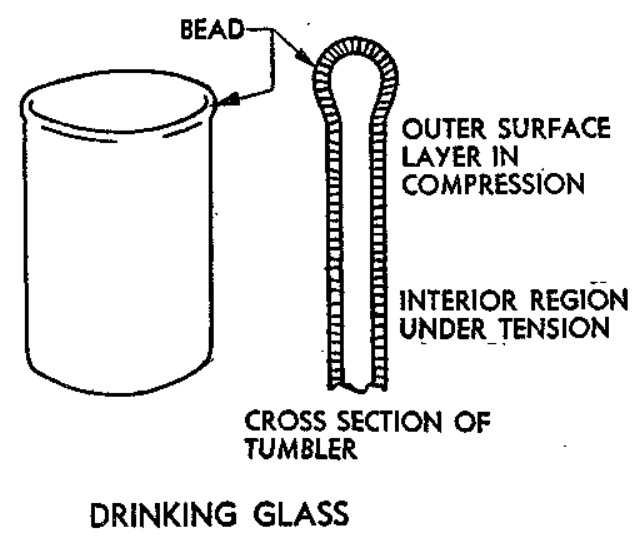

an obvious remedy for this situation is to provide adequate drainage under the concrete and an effective protective coating on the upper surface of the concrete.

\title{
AN APPLICATION OF THE POINT-OF-DIVISION FORMULA
}

\author{
R. F. GRAESSER \\ University of Arizona, Tucson, Arizona
}

The ordinate of the point $P(x, y)$ dividing the line segment from the point $P_{1}\left(x_{1}, y_{1}\right)$ to the point $P_{2}\left(x_{2}, y_{2}\right)$ in the ratio $r_{1}: r_{2}$ is

$$
y=\left(r_{1} y_{2}+r_{2} y_{1}\right) /\left(r_{1}+r_{2}\right) \text {. }
$$

As an application of this formula, suppose we need to interpolate in the accompanying table, or any similar numerical table.

TABLE

\begin{tabular}{l|c|c}
\hline Annual Rate of Interest & $3 \%$ & $3.5 \%$ \\
Amount of $\$ 1$ for 10 years & 1.3439 & 1.4106 \\
\hline
\end{tabular}

Suppose we want the compound amount of $\$ 1$ for ten years at, say, $3.36 \%$. The amounts given may then serve as ordinates of the points $P_{1}$ and $P_{2}$. Taking $y_{1}=1.3439$, and $y_{2}=1.4106$, we may let $r_{1}=0.36$ and $r_{2}=0.14$ in (1). Then $y$ becomes the required amount of $\$ 1$ as obtained by linear interpolation.

$$
\begin{aligned}
& y=(0.36[1.4106]+0.14[1.3439]) /(0.36+0.14) . \\
& y=2(0.50782+0.18815) \\
& y=1.3919
\end{aligned}
$$

This result is very conveniently obtained if a computing machine is available. 